\title{
IMPROVEMENT OF POWER QUALITY USING SERIES ACTIVE POWER FILTER
}

\author{
Archana Patnaik ${ }^{1}$, R.K.Sharma ${ }^{2}$ \\ ${ }^{I}$ Department of Electrical Engineering, Lovely Professional University, Punjab, India \\ ${ }^{2}$ Department of Electrical Engineering, Lovely Professional University, Punjab, India
}

\begin{abstract}
This paper deals with the design and implementation of series active power filter for the improvement of power quality. In power system there is a nonlinear load which seems to be the prime sources of harmonic distortion. A dissimilar type of load creates nonsinusoidal current from the mains, which give rise to harmonic distortion and affect the power quality. Classic filters may not have satisfactory solutions but series active filter give quite better results and is utilized for the mitigation of harmonics and it also reduces the THD level. Results obtained shows that this scheme is able to mitigate the harmonic problem and can improve the quality of power. This is done by simulation using MATLAB software.
\end{abstract}

Keywords-Series Active Power Filter(SPAF), Nonlinear load, Power quality, Total Harmonic Distortion(THD).

\section{INTRODUCTION}

There have been seen a rapid increment of power electronics based loads connected to the system in previous years. Such types of loads precede non-sinusoidal current from the main supply which influences the power quality by generating harmonic distortion. These types of loads are generally nonlinear loads in power distribution systems which are the prime sources of harmonic distortion. Power quality is the conception of powering and prohibiting sensitive equipment in aspect that is suitable to the operation of that equipment. Nowadays people want the quality of power and the power quality is simply the co-operation of electrical power with electrical equipment. If the electrical equipment performs correct and reliable manner without being obstructive or pressurized, we would say that the electrical power is of good quality. In the case, if the electrical equipment breakdown is unreliable, or is obstructive during normal usage, we would guess that the power quality is poor.

Harmonics are the major cause of power supply; it degrades the power factor and increases the electrical losses. These are electric voltages and currents that are appear on the electric power system which shows as a result of certain kinds of electric loads. A harmonic is the term used for unwanted and possibly destructive current flow. Harmonics results from the distortion of sine wave caused naturally by nonlinear load. Most significant harmonics are the low order integral harmonics, typically from the 2nd to the 31 st. Additionally, harmonics are caused by and are the by-product of modern electronic equipment such as personal or computers, laser printers, fax machines, telephone systems, stereos, radios, TV's, adjustable speed drives and other equipment. When a sinusoidal voltage is applied to the nonlinear load we get the distorted current, an increase in voltage may cause to double the current. This is the main source of harmonic distortion in power system. This distortion can be reduced by using various techniques such as passive and active filter. Passive filter causes resonance problem thus it effect the stability of the system while an active power filter is used for various technologies by producing specific currents components which cancels the harmonic currents components caused by nonlinear loads. Various topologies of active filters have been proposed for harmonic mitigation. There are two major approximations that have appeared for harmonic distortion, namely time domain and frequency domain methods. In this paper series active power filter is simulated which is used for the reduction of voltage and current harmonics. In this simulation of series APF a controller is used in which the reference voltage first generated and then these reference voltages are compared with the actual voltages through which an error signal is generated and helps to reduce the distortion in harmonics.

\section{SERIES ACTIVE POWER FILTER}

Series APF are operated mainly as a voltage regulator and a harmonic isolator between the nonlinear load and the utility system. The series connected filter protects benefit the consumer from an inadequate supply voltage quality. This type of approach is mostly recommended for compensation of voltage unbalances and voltage sags from the AC supply and for low applications and represents economically attractive alternatives to utility power system, since no energy storage is energy and the overall ratings of the components is smaller. The advantages of series active power are- automatic compensation for varying loads, resonance free, does not affect power factor and can be combined with passive filter network. 


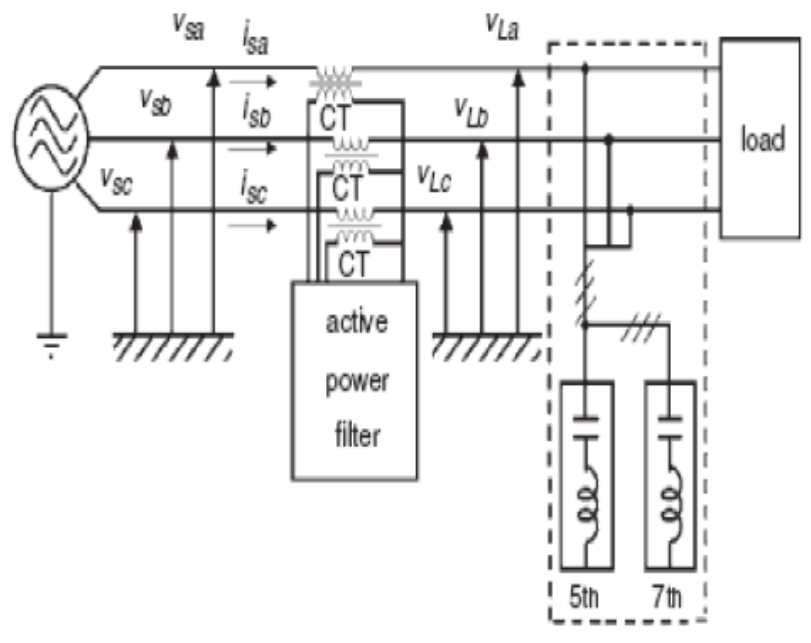

Fig-1 Circuit Configuration of Series APF

\section{SIMULATION AND PERFORMANCE OF SERIES ACTIVE POWER FILTER WITHOUT FILTER}

Now days in modern electrical system there are various types of load like commercial loads, industrial loads etc. The system supplies power to these different types of load, such type of sources produces harmonic distortion which effects the equipment which is connected in the system. The system without filter Fig-2 creates many distortions which is responsible for many power quality disturbances. Mostly harmonics are the integer multiple of the frequency.

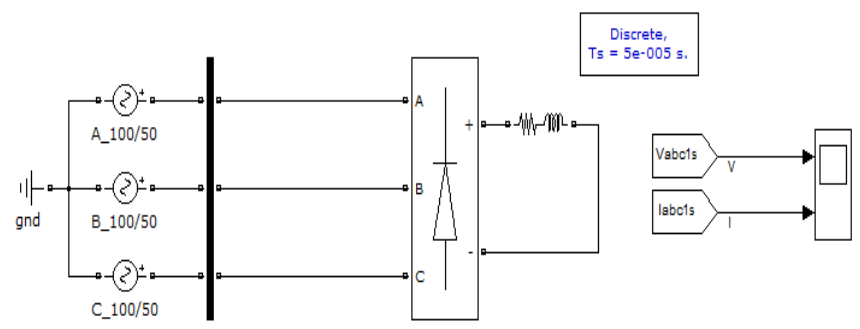

Fig-2 System without Series APF

\section{SIMULATION AND PERFORMANCE OF SERIES ACTIVE POWER FILTER WITH FILTER}

In electrical system nonlinear loads are connected to the power system and it is supplied by the non-sinusoidal current. In this Series active power filter is used, harmonics are eliminated and it is given by a controller. First the reference voltages are produced and then these references voltages are compared with the actual load voltages and the error signal is given to the controller to generate the firing pulses for the switch of the inverter. The output of the series active power filter is connected to the main lines through series transformers so as to make the load voltage purely sinusoidal the harmonic voltage is absorbed or injected by the filter.

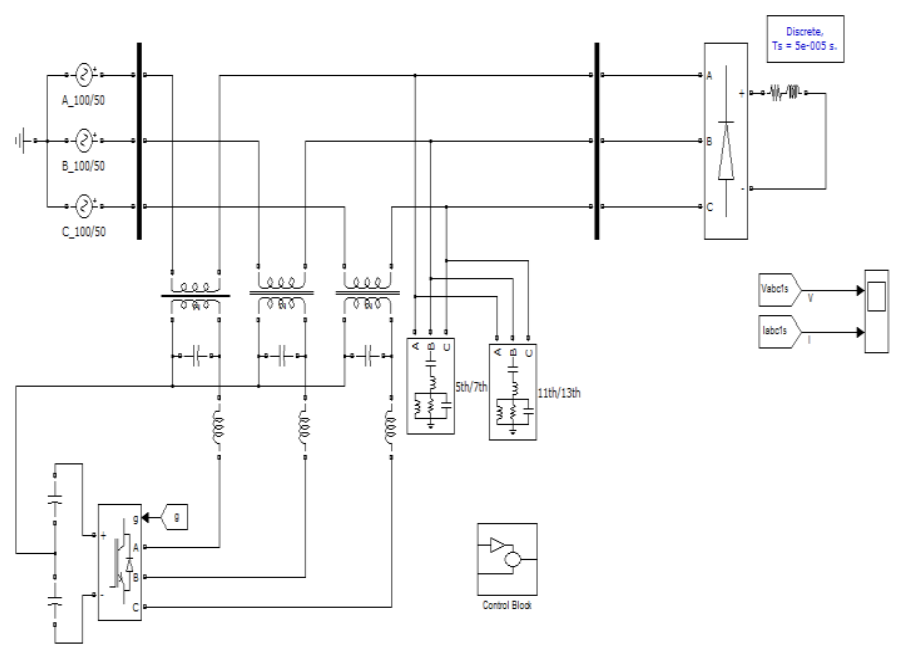

Fig-3 System with Series APF

\section{RESULTS}

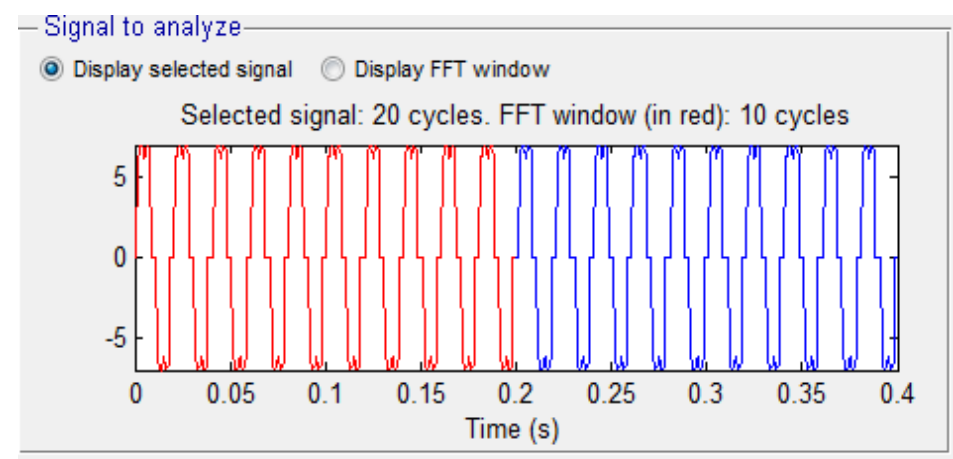

Fig-4 Signal system which is to be analyzed (without filter)

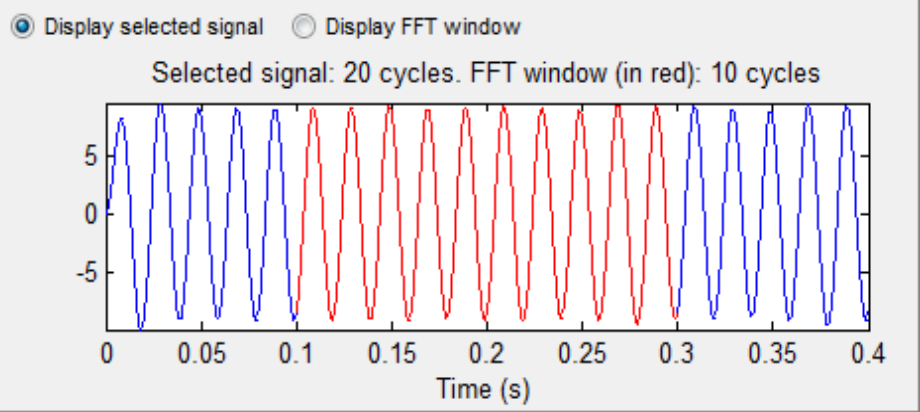

Fig-5 Signal system which is to be analyzed (with filter) 


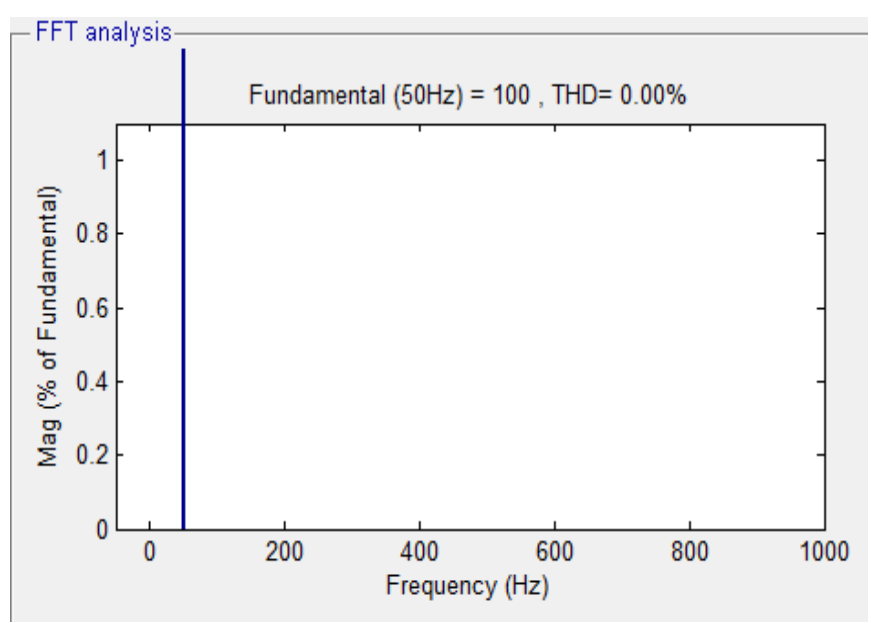

Fig-6 Signal to analyse without filter.

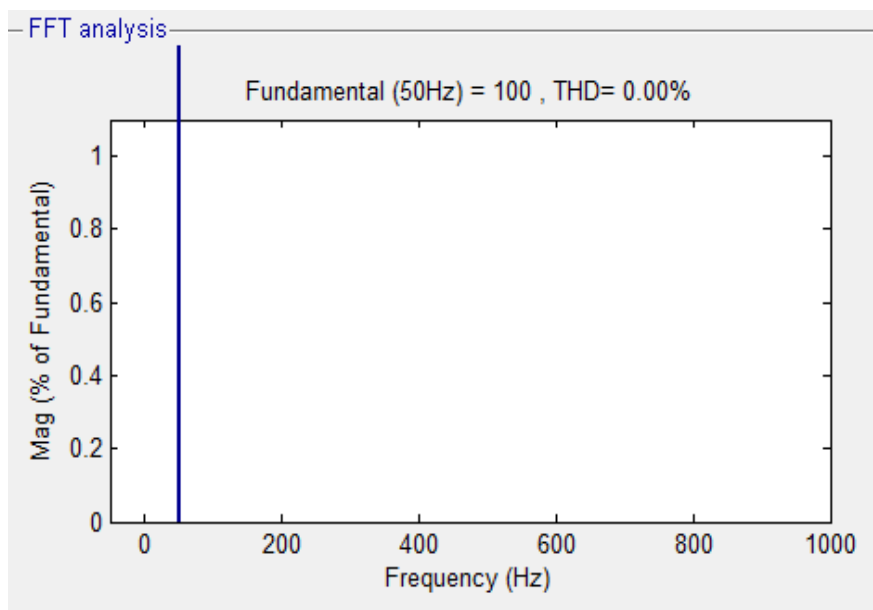

Fig-7 Signal to analyse with filter.

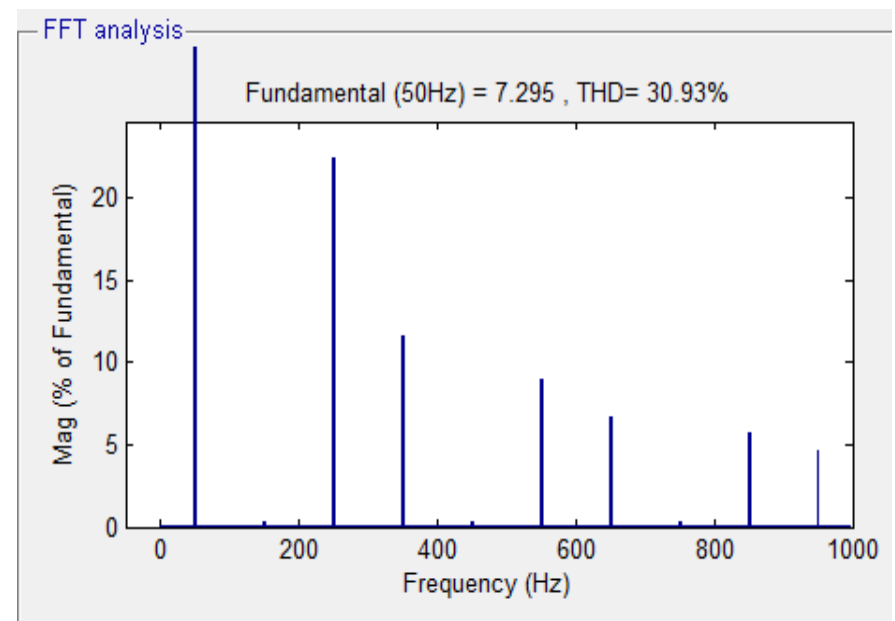

Fig-8 Bar representation of the signal (without filter)

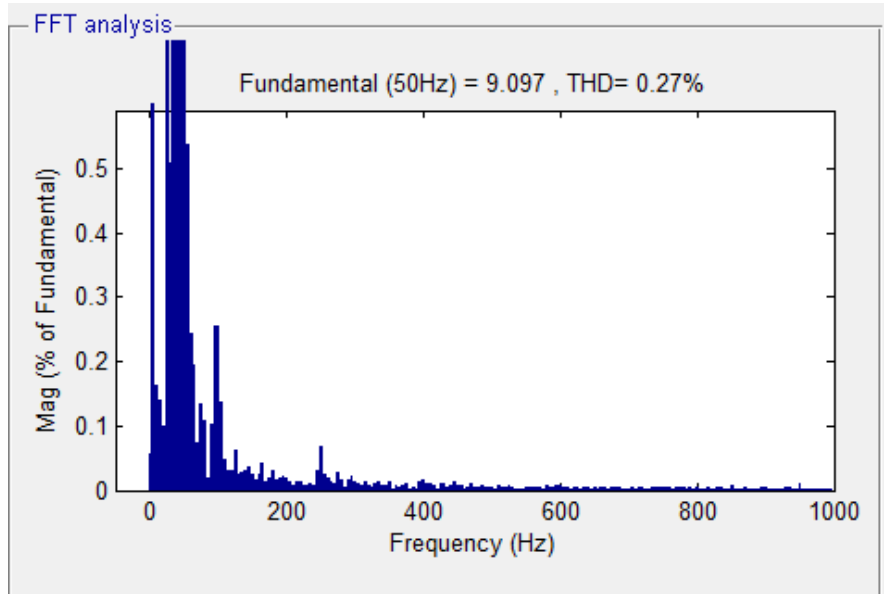

Fig-9 Bar representation of the signal (with filter).

The bar representations (fig.8 and fig.9) of signals (fig.4 and fig.5) shows the difference in total harmonic distortion between the system with and without Series APF, THD was $30.93 \%$ before implementing Series APF and THD reduced to $0.27 \%$ after the implementation of Series APF.

\section{CONCLUSIONS}

A MATLAB based model of the series active power filter has been simulated for the RL load. The simulation results show that the harmonics produced due to voltage and current are reduced very effectively by utilizing the series active power filter.

\section{FUTURE SCOPE OF THIS WORK}

In this work, the total harmonic distortion is reduced using series active power filter but further this THD can be much more reduced by HPF for the better performance of power quality and can be considered for future study. Also this work can be used by the help of various FACTS devices and many more techniques because harmonics are still a major problem and this can be studied further.

\section{REFERENCES}

[1] G. Chang and W. Chen, "A new reference compensation voltage strategy for series active power filter control," Power Delivery, IEEE Transactions on, vol. 21, no. 3, pp. $1754-1756$, jul. 2006.

[2] S. Inoue, T. Shimizu, and K. Wada, "Control methods and compensation characteristics of a series active filter for a neutral conductor," Industrial Electronics, IEEE Transactions on, vol. 54, no. 1, pp. $433-440$, feb. 2007.

[3] "Improvement of the electric power quality using series active and shunt passive filters," Power Delivery, IEEE Transactions on, vol. 25, no. 2, apr. 2010. 
[4] M.H. Rashid, Power Electronics, Circuits, Devices, and Applications 2nd ed., Prentice Hall 1993 "An exploration of the state-of- the-art in power conversion techniques and power semiconductor devices."s

[5] S. Buso, L. Malesani, P. Mattavelli, Comparison of current control Techniques for Active power Filter Applications, IEEE Transactions on Industrial Electronics, Vol.45, no.5, pp.722-729, Oct 1998.

[6] J. Wiseman and $\mathrm{B}$. Wu, "Active damping control of a high-power pwm current- source rectifier for linecurrent thd reduction," Industrial Electronics, IEEE Transactions on, vol. 52, no. 3, pp. $758-764$, jun. 2005.

[7] Luis A. Morán, Juan W. Dixon, Rogel R. Wallace, “A Three- Phase Active Power Filter Operating with Fixed Switching Frequency for Reactive Power and Current Harmonic Compensation", IEEE Trans. on Ind.Electron, vol. 42, $\mathrm{N}^{\circ} 4$, August 1995.

[8] George Adam, Alina G. Stan (Baciu) and Gheorghe Livinţ, "A MATLAB-simulink approach to shunt active power filters" Technical University of Iaşi 700050, Iaşi, Romania.

[9] Roger C. Dugan, Mark F. Mcgranaghan, Surya Santos and H. Wayne Beaty, Electrical power system Quality, Tata McGraw Hills publications, (2002).

[10] T.Kulworawanichpong, K-L.Areerak, K-N.Areerak, and S.Sujitjorn, "Harmonic Identification for Active Power Filters Via Adaptive Tabu Search Method", LNCS (Lecture Notes in Computer Science), SpringerVerlag Heidelberg, Volume 3215, 2004, pp. 687-694.

[11] Nur Izzati Nadiah Binti Ishak, simulation of active power filter using matlab/simulink, universiti teknikal malaysia melaka, 22 april 2010.

[12] Bhim Singh, Kamal Al Haddad and Ambrish Chandra, A Review of Active Filters for Power QualityImprovement, IEEE Trans on Industrial Electronics, Vol.46, No.5, October 1999

[13] G. Eason, B. Noble, and I.N. Sneddon, "On certain integrals of Lipschitz-Hankel type involving products of Bessel functions," Phil. Trans. Roy. Soc. London, vol. A247, pp. 529-551, April 1955. 